Plural ha sido la celeste historia. Consolidación y decadencia de las redes de poder de la elite modernizadora rioplatense, 1850-1930.

Daniele Bonfanti

páginas / año 7 - n 15 / ISSN 1851-992X / pp. 29-47 / 2015

http://revistapaginas.unr.edu.ar/index.php/RevPaginas/index

\title{
Plural ha sido la celeste historia. Consolidación y decadencia de las redes de poder de la elite modernizadora rioplatense, 1850-1930
}

\author{
Plural ha sido la celeste historia. Consolidation and decline of power \\ networks of Rio de la Plata elite, 1850-1930
}

\author{
Daniele Bonfanti \\ Agencia Nacional de Investigación e Innovación, Uruguay \\ tanobonfanti@gmail.com
}

\section{Resumen}

En este trabajo se examina la evolución de las redes sociales de un grupo empresarial homogéneo que, a partir del último cuarto del siglo XIX, impulsó en Uruguay un entramado de relaciones con vocación de "red de poder". A pesar del ascenso social de estos empresarios sus redes de poder fracasaron. El artículo intenta ofrecer alguna explicación sobre este proceso.

\section{Palabras claves}

Redes sociales, Historia del Uruguay, Historia de las elites.

\begin{abstract}
This paper examines the evolution of social networks of a fairly homogeneous group of entrepreneurs. From the last quarter of the 19th century, this group promoted in Uruguay a framework of relations with the aim of "red power". Despite the social rise of these innovative entrepreneurs, these power networks failed. The work tries to offer some explanation about this process.
\end{abstract}

\section{Keywords}

Social Networks, History of the Uruguay, History of the elites. 


\section{Plural ha sido la celeste historia}

\section{Introducción}

Este trabajo constituye un acercamiento al proceso de conformación, consolidación y decadencia de un sector modernizador de la elite uruguaya, implicado en las transformaciones de la producción agropecuaria, a partir del análisis de las densas redes sociales que se impulsaron para difundir nuevas técnicas y conocimientos. ${ }^{1}$ Este entramado de relaciones sociales, que tuvo su centro en la Asociación Rural del Uruguay (en adelante ARU) tuvo una vocación de "red de poder", aunque sólo parcialmente logró condicionar las decisiones políticas generales.

El artículo se centrará de manera específica en la trayectoria de la familia Vidiella, caso ejemplarizante de este sector social de origen extranjero que realizó su ascenso entre 1860 y 1870, impulsó un conjunto de innovaciones productivas, apostó decididamente a la viabilidad del país como Estado-Nación y participó activamente en la ARU desde su fundación hasta su crisis de representación de principios del siglo XX.

Quiero subrayar el carácter sustancialmente descriptivo de esta investigación. La historiografía uruguaya ha recurrido frecuentemente a la caracterización de categorías sociales "fuertes", aparentemente bien definidas que, sin embargo, han demostrado tener escaso valor explicativo. Creo que un trabajo con un fuerte contenido empírico pueda contribuir a superar estas categorizaciones imprecisas y a mejorar el enfoque teórico sobre el tema.

\section{La ARU y la clase alta rural}

Uruguay (como el resto de América Latina) atravesó entre el último cuarto del siglo XIX y las primeras décadas del siglo XX, un cambio estructural, definido como proceso de modernización, que optimizó su incorporación a la economía mundial como país agroexportador, llevó a la formalización de instituciones políticas que permitieran cerrar los conflictos derivados del proceso de independencia y que le otorgaran estabilidad y viabilidad como Estado independiente, impulsó una pronunciada urbanización pautada por un espectacular crecimiento demográfico, a su vez determinado por la inmigración proveniente de la Europa mediterránea.

La constatación de estas transformaciones estructurales impuso, a la historiografía uruguaya, un conjunto de cuestiones de no fácil resolución. Insertando la modernización en un marco que debía confirmar que Uruguay, como realidad nacional preexistente, era el resultado "natural" de la evolución histórica y

\footnotetext{
1 Una primera versión de este trabajo ha sido presentada en las $X V$ Jornadas Interescuelas/Departamentos de Historia que se realizaron entre el 16 y el 18 de septiembre de 2015 en Comodoro Rivadavia (Argentina). Quisiera agradecer los comentarios de la Dra. Marta Bonaudo y de los otros participantes en la mesa, que permitieron mejorar los enfoques de esta investigación.
} 


\section{Daniele Bonfanti}

que ratificara que "lo esencial de la economía nacional derivaba de la ganadería"2, esta visión debía hallar un sector dominante que tuviera las características esperadas (rasgos reducidos y homogéneos, control de la política y la economía) pero también explicar las peculiaridades del reformismo liberal de las primeras décadas del siglo XX (particularmente su legislación social) y, sobre todo, justificar el "fracaso" de estas transformaciones estructurales que habrían llevado hacia un "desarrollo bloqueado" en los siglos XIX y XX. ${ }^{3}$

Según esta interpretación, la estandardización de la legislación y la ampliación "herética" para la época de sus funciones, inaugurada por el primer gobierno militar de Lorenzo Latorre (1876-1879), hicieron que el Estado liberal asumiera en Uruguay "roles atípicos", que estuvieron a la base del posterior intervencionismo económico y de la misma "excepcionalidad" uruguaya en el contexto latinoamericano. ${ }^{4}$

Este fenómeno fue posible sustancialmente por las "estructuras mentales" que cercenaron el comportamiento de la clase dirigente a dos posibles caminos opuestos y excluyentes.

Por un lado, un sector de origen "nacional", que se demostró reacio a todo tipo de innovación y que se involucró en actividades económicas "tradicionales": el comercio, las inversiones especulativas en bienes raíces urbanos, las actividades financieras no menos especulativas y modalidades "primitivas" de explotación ganadera. Las transformaciones estructurales dictadas por el avance del sistema capitalista mundial llevaron a un inevitable empobrecimiento de esta "oligarquía tradicional" o "patriciado" que, para conservar su cuota de poder, se hizo sistemáticamente de todos los cargos públicos a disposición, a través de su activa participación en la política. 5

Por el otro, un sector "moderno", compuesto por extranjeros o por hijos de extranjeros -condición que la historiografía uruguaya considera equivalente por razones culturales-, caracterizado por una mentalidad emprendedora capitalista y, por ende, interesado exclusivamente por el rendimiento de sus inversiones. Esta elite "moderna" intentó mantenerse al margen de la política y, de manera específica, de las modalidades "tradicionales" de resolución de los conflictos a través de levantamientos, revoluciones y enfrentamientos armados, aunque sufrió sus consecuencias en términos de pérdidas económicas.

Este dicotómico comportamiento, que llevó a un cierto divorcio entre política y poder económico, fue acompañado por la temprana profesionalización del elenco político, posible por los elevados sueldos otorgados a los gobernantes,

\footnotetext{
2 José Pedro Barrán y Benjamín Nahum. Historia rural del Uruguay moderno (1851-1885). Montevideo, EBO, 1967; Tomo I; pág.8.

3 Ídem., pág. 315.

4 José Pedro Barrán y Benjamín Nahum. Batlle, los estancieros y el Imperio Británico. El nacimiento del batllismo. Montevideo, EBO, 1986; Tomo III; págs. 19 y 41.

5 Carlos Real de Azúa. El patriciado uruguayo. Montevideo, EBO, 1981.
} 


\section{Plural ha sido la celeste historia}

que les permitió "desligarse de la presión de las clases altas del país por su control casi monopólico del aparato gubernamental" ${ }^{6}$

El margen de autonomía de esta clase política profesionalizada se enfrentó con la estructura del país. La ganadería, única actividad económica considerada rentable, se habría caracterizado por una casi nula capacidad de evolución. A pesar de que se verificaran algunos cambios, éstos terminaron fortaleciendo los rasgos estructurales originarios y las continuidades, ya que "la demanda mundial no exigía una conversión total de lo antiguo a lo nuevo".7 Así que, mientras "Perú tuvo sus ciclos de la plata y el guano; Chile los del trigo, el salitre y el cobre; Brasil los de la madera, el azúcar, el oro y los diamantes, el café"8, en Uruguay al cuero se sumó al tasajo, la lana al cuero y el tasajo, las carnes vacunas refrigeradas a la lana y el cuero en un proceso en el cual "ningún producto nuevo desplazó totalmente al precedente". ${ }^{9}$ Cada uno de estos ciclos económicos tendría su correspondencia en la evolución política e institucional, que también se habría desarrollado de manera autónoma pero conservando los elementos primordiales y distintivos de la realidad social uruguaya: los partidos colorado y blanco. Justamente en esta continuidad residiría "lo original" de la evolución económica de Uruguay, donde "lo más remoto sobrevive en el presente". 10

Según esta reconstrucción historiográfica, una de las consecuencias más inmediata de este proceso fue que la estructuración social de la campaña fue muy sencilla y polarizada, debido a que "exagerando algo la nota", los pequeños y limitados cambios "sirvieron en última instancia al mantenimiento del 'establishment' ganadero ya definido en 1800"11, visto que "hubo modificaciones en el sector social del campo, no desplazamientos".12

En este marco, de "civilización ganadera que nunca renegó de si misma, fiel a la tierra y al animal como hostil al cultivo", las pautas comportamentales de los grupos sociales estarían predeterminadas por la "vocación ganadera" del país, y su consecuente "mentalidad pastoril", que fortalecieron el "conservadurismo visceral" de las "estructuras mentales", que "no pudo menos que reflejarse en toda la vida nacional desde la política, a la economía y la cultura". Esta tendencia a "conservar [...] y negarse con pasión a las transformaciones"13 del mundo pastoril habría determinado una resistencia cultural a lo nuevo que se evidenciaría tanto en el tradicionalismo generalizado de la sociedad como, más especificadamente, en la lentitud y la repulsa hacia las innovaciones productivas. En consecuencia, entre las

\footnotetext{
6 José Pedro Barrán y Benjamín Nahum. Batlle, los estancieros y el Imperio Británico. Un diálogo difícil 1903-1910. Montevideo, EBO, 1981; Tomo II; pág.15.

7 José Pedro Barrán y Benjamín Nahum. Historia rural del Uruguay moderno. Agricultura, crédito y transporte bajo Batlle (1903-1914). Montevideo, EBO, 1978; Tomo VII; pág.178.

8 Ídem., pág. 178.

9 Ídem.

10 Ídem., pág. 180.

11 Ídem., pág. 178.

${ }^{12}$ José Pedro Barrán y Benjamín Nahum. Historia rural del Uruguay moderno. Recuperación y dependencia (1895-1904). Montevideo, EBO. 1973; Tomo III; pág. 16.

13 José Pedro Barrán y Benjamín Nahum. Historia rural..., Op. Cit.; pág. 178.
} 


\section{Daniele Bonfanti}

dos posibles formas de actuación de la elite, el comportamiento "moderno" y el "tradicional", este último terminó prevaleciendo.

La estructura social, según esta visión historiográfica, estaría definida y pautada por estas "mentalidades" que, a su vez, habrían llevado al enfrentamiento o la colaboración entre una clase política con un cierto margen de autonomía y una homogénea "clase alta", conformada por el llamado "alto comercio montevideano", los inversores extranjeros y, sobre todo, una todopoderosa clase terrateniente. Debido al papel clave de la ganadería en la economía del país, este sector terrateniente, tuvo una absoluta capacidad de subordinar a los restantes sectores sociales y encontró en la ARU, a veces su organismo de representatividad y de presión que, a través de sus asesorías sólo aparentemente técnicas, "hacía $o$ impedía que el gobierno adoptase ciertas medidas jurídicas o impositivas"14, condicionando, frenando u obstaculizando todo tipo de decisión institucional. Se admite que la ARU nació como instancia del empresariado "moderno", dispuesto a optimizar la inserción del país en el mercado internacional a través de innovaciones en la ganadería. Sin embargo, debido al substrato ideológico "pastoril", ya la segunda generación de estos innovadores comenzó a imitar "las formas del ocio y el derroche urbanos, típicas de la clase alta tradicional". ${ }^{15}$

He intentado en otra instancia presentar unas críticas a esta interpretación historiográfica. ${ }^{16}$ Aquí retomaré sintéticamente algunos elementos útiles para mi razonamiento posterior.

Creada en 1871 por un pequeño grupo de empresarios que tenían en común la preocupación de promover innovaciones en el ámbito productivo (no necesariamente agropecuario) y modalidades más modernas de gestión empresarial, hasta la década de 1910, la ARU no fue una asociación conformada exclusivamente por productores pecuarios ni por empresarios que querían especializarse como estancieros. La convicción de que era necesario diferenciar la producción para responder a la demanda del mercado interno y para multiplicar la calidad y el tipo de bienes en el comercio agroexportador, hizo que la gremial se empeñara en promover nuevos cultivos, particularmente la vitivinicultura. ${ }^{17}$ Por otra parte, existió una visión compartida sobre la necesidad de que el país, para poder consolidarse definitivamente, debía sufrir una transformación que implicara una reducción del peso de la ganadería a favor del incremento del espacio agrícola. 0 , dicho en palabras de su fundador y secretario perpetuo Domingo Ordoñana, la

\footnotetext{
${ }^{14}$ José Pedro Barrán y Benjamín Nahum. Historia rural del Uruguay moderno (1851-1885)..., Op. Cit., pág. 356.

15 Ídem., pág. 343.

16 Daniele Bonfanti. Una mina más rica que las de oro del Potosí. Elites, técnicos, instituciones y trabajadores en el nacimiento de la vitivinicultura uruguaya (1870-1930), Tesis de doctorado inédita. Madrid, Universidad Complutense - Instituto Universitario de Investigación Ortega y Gasset, 2014. http//eprints.ucm.es/29598/1/T35973.pdf, págs. 72-83 y 135-142.

17 Es significativo, en este sentido, que desde 1885 hasta 1898 todos los presidentes de la asociación fueron vitivinicultores (aunque tuvieran inversiones en otros sectores): Luis De la Torre (que asumió por segunda vez la dirección de la gremial entre 1885 y 1887), Luis Lerena Lenguas (1887-1890), Federico Vidiella (1890-1893) y Diego Pons (1893-1898).
} 


\section{Plural ha sido la celeste historia}

ARU tenía el papel de acercar Uruguay a los "nuevos tiempos, los magnos tiempos de la transición de la primitiva vida pastoril a la regular vida agrícola, que es la vida que forma la familia, la que da hábitos morales".18

En este sentido, aunque el sector agropecuario fuera considerado como el más dinámico (y los productores como los actores fundamentales para impulsar el desarrollo del país), el problema básico de la ARU fue el "progreso del país", como quedó claro desde la primera circular que convocaba a la constitución de la gremial, el $1^{\text {o }}$ de mayo de $1871 .{ }^{19}$ En este afán de representar a la totalidad de los sectores modernizadores, el rasgo ruralista de la gremial no debe entenderse en términos territoriales -ciudad versus campo- sino valorativos: la campaña era el lugar del esfuerzo, el trabajo y la riqueza "útil", la ciudad era el centro de la especulación financiera, pero también el núcleo potencial desde donde podían derramarse las reformas estructurales. ${ }^{20}$

En consecuencia, como ha sido relevado para otras gremiales del cono sur, ${ }^{21}$ la ARU presentó insalvables contradicciones entre sus cometidos y su programa. El contexto rural era presentado como el ámbito de las transformaciones necesarias para modificar la estructura socioeconómica del país y los productores rurales eran considerados como la fuerza de cambio. Pero el uno y los otros tenían que sufrir un cambio radical para cumplir con su función transformadora. El mundo rural era, así, propulsor de los cambios pero también ámbito que era necesario transformar, algo que implicaba poner en discusión algunos aspectos fundamentales del modelo agroexportador y, particularmente en los períodos de crisis económicas, la misma estructura productiva de la campaña uruguaya, con especial énfasis en las denuncias contra el latifundio. ${ }^{22}$ Probablemente también por esto la ARU nunca logró reunir un número representativo de adherentes.

Tampoco pudo condicionar de manera determinante las políticas estatales, ni siquiera durante el gobierno de Lorenzo Latorre, considerado por la historiografía como el período de mayor gravitación de la asociación. Esto independientemente del hecho de que existió, particularmente en el último cuarto del siglo XIX, una cierta cohesión de objetivos entre el Estado y este grupo modernizador de la elite, sustancialmente sobre la necesidad de afirmar los derechos liberarles sobre la propiedad privada de la tierra y, particularmente,

\footnotetext{
18 Domingo Ordoñana. Pensamientos rurales sobre necesidades sociales y económicas de la república, 1892. Montevideo, Imprenta Rural; Tomo I; pág.2.

${ }^{19}$ Documentos relativos a la fundación de la Asociación Rural del Uruguay. Montevideo, Imprenta del Siglo, 1871; pág.3.

20 Véase, al respecto, las consideraciones de Luis de la Torre, entonces presidente de la ARU, sobre la necesidad de que Montevideo "centro de civilización" interviniera a favor de la "campaña desierta” Revista de la Asociación Rural del Uruguay, año III, n 42. Montevideo, 1-9-1874; pág.413.

21 Tulio Halperín Donghi. José Hernández y sus mundos. Buenos Aires, Sudamericana, 1985; págs. 225-261 y “Clase terrateniente y poder político en Buenos Aires (1820-1930)”, en La formación de la clase terrateniente bonaerense. Buenos Aires, Prometeo, 2007; págs. 93-112; Roy Hora. Los terratenientes de la pampa Argentina. Una historia social y política, 1860-1945. Buenos Aires, Siglo XIX, 2005; págs. 9-10 y 18.

${ }^{22}$ José Pedro Barrán y Benjamín, Nahum. Historia rural del Uruguay moderno. La crisis económica (1886-1894). Montevideo, EBO; Tomo II, 1971; págs. 393-428.
} 


\section{Daniele Bonfanti}

mantener la pacificación interna, condición sine qua non para impulsar un desarrollo virtuoso del país.

Según los dirigentes de la ARU, la paz habría atraído inmigrantes que habrían difundido nuevas técnicas de cultivo, habría sedentarizado a los pobres rurales que habrían encontrado en los nuevos cultivos una mejora para su situación económica y moral, el incremento demográfico habría permitido conformar un mercado interno, los nuevos cultivos habrían garantizado una mayor diferenciación de las exportaciones, la riqueza obtenida habría otorgado una creciente viabilidad al país, permitiendo incrementar la diferenciación productiva y atraer nuevos inmigrantes, en un círculo virtuoso inagotable. Este proyecto indica, entre otras cosas, la honda preocupación para la integración jerárquica de los peones desplazados por la afirmación de los derechos liberales de propiedad y para los agricultores pobres -el llamado "proletariado rural"- que fue peculiar de la gremial uruguaya, a diferencia de las homólogas latinoamericanas.

De todas maneras, a parte esta comunión de preocupaciones, la ARU nunca fue una organización ideológicamente monolítica. $\mathrm{Su}$ fundación parecería corresponder también a la necesidad de encontrar un espacio neutral donde las diferentes componentes de la elite modernizadora pudieran confrontar las personales experiencias de innovación. Además, el debate sobre cómo proceder para impulsar las transformaciones esperadas fue bastante intenso y estalló en la década de 1890, cuando se cumplió un relevo generacional en su directiva.

Por último, la historiografía ha insistido en que la ARU fue constituida sustancialmente "por hombres no pertenecientes a la jerarquía social tradicional". ${ }^{23}$ A pesar de que esto sea cierto (así como es verdadero que miembros de la "jerarquía social tradicional" participaron en la ARU y promovieron innovaciones) creo necesario insistir en que, para el caso de Uruguay el concepto de "oligarquía tradicional" o "oligarquía colonial" tiene un sentido relativo. Buena parte de lo que se define como elite "tradicional" en la década de 1870 se había conformado después de la finalización de las guerras de independencia y la Guerra Grande, es decir entre 1830 y 1850. En su ascenso sustituyó a aquella porción de la anterior oligarquía "tradicional" que se había consolidado económica y políticamente entre 1770 y 1810 y que no supo ni pudo superar la crisis provocada por los movimientos revolucionarios y bélicos del período. Los relevos tan frecuentes en la elite sugieren que ningún sector logró afianzarse por el tiempo suficiente para poderse considerar como "tradicional" y muestran una marcada movilidad social, característica de países "nuevos" y con escasa población. De manera que el recurso a una conceptualización tan categórica debería, por lo menos, matizarse.

${ }^{23}$ Barrán José Pedro y Benjamín Nahum. Historia rural del Uruguay moderno (1851-1885)..., Op. Cit., pág. 319. 


\section{Plural ha sido la celeste historia}

\section{Redes primarias y redes "científicas" en la fase de ascenso social}

Francisco Vidiella nació en Montroig (Tarragona) en 1820 y llegó, con sus hermanos Juan y José, a Uruguay en 1837 siguiendo al padre, exiliado por su participación en las guerras carlistas. La familia Vidiella instaló una casa de comercio en la ciudad de Salto, nodo estratégico del circuito de intercambio fluvial, y posteriormente una sucursal en Uruguayana (Río Grande do Sul, Brasil).

En 1857, Francisco se trasladó a Montevideo, que se transformó en su residencia personal y en el centro de las actividades económicas, al mando de la firma Vidiella y Escalada primero y Vidiella y Cía. después, especializadas en la importación de productos catalanes y españoles, muy probablemente como "habilitado" de la casa Ferrés y Carrau de Vilasar de Mar (Barcelona). ${ }^{24}$

Su hermano Juan se instaló en Concordia (Argentina) en el marco de la expansión de la firma "madre". Después, complementando la actividad empresarial con la de diplomático "informal", pasó a Cádiz para luego residir entre Montevideo y Valencia, colaborando de forma intermitente en las actividades de su hermano, particularmente en la puesta en marcha de un viñedo. ${ }^{25}$

Muy llamativa es la "desaparición" de José, sobre el cual, luego de un brevísimo (e incierto) paréntesis en las actividades comerciales familiares, prácticamente no se tiene más noticias. ${ }^{26}$ Los pocos datos a disposición parecerían indicar que tempranamente las relaciones entre José y sus dos hermanos se enfriaron hasta romperse.

Francisco y Juan se casaron con hijas de empresarios de origen catalán, aunque ya nacidas en Uruguay, que tenían una destacada inserción en Salto, respectivamente Dorotea Fortet y Adelaida Andreu. ${ }^{27}$

El proceso de consolidación y expansión de Vidiella y Cía. siguió los rasgos comunes a otras empresas exitosas del período. La estructura organizativa de la firma se superpuso a la de la familia; el comercio atlántico desplazó paulatinamente el intercambio a nivel regional que, de todos modos, jamás fue completamente abandonado y se fomentó la diferenciación de las actividades, colocando los activos en diferentes ámbitos económicos (comerciales, financieros, industriales y agrícola) en un proceso que permitió conseguir rápidamente la autonomía respecto a la empresa "habilitadora" española.

\footnotetext{
${ }^{24}$ Véase Archivo Carlos Varzi (en adelante ACV), Carpeta s/caratular, Copia de una carta de Pablo Varzi a Diego Pons y Federico R. Vidiella, Colón, 12-3-1903 y ACV, Carpeta caratulada Cía. automóviles P.V. Solar Colón, Carta de Federico R. Vidiella a Pablo Varzi, Montevideo (¿?), 17-81899.

25 Luis De la Torre. "Viticultura". Revista de la Asociación Rural del Uruguay, n¹2, año XIV. Montevideo, 30-6-1885, págs. 362-365 y Archivo de la Asociación Rural del Uruguay (en adelante AARU), Libro Correspondencia Oficial años 1875-1898, nota a Félix Buxareo. Montevideo, 5-9-1877, f.194.

${ }^{26}$ José María Fernández Saldaña. Diccionario uruguayo de biografías 1810-1940. Montevideo, Amerindia, 1945, pág. 1319.

${ }^{27}$ De José poco se sabe. Probablemente casó en primeras nupcias con la italiana Alejandra Della Cella (y es posible que este enlace hizo aflorar las tensiones interfamiliares) y en segundas con Lucía Pons.
} 
El comercio tendió a perder peso en el conjunto de las inversiones, a pesar de que siempre estuvo insertado en las actividades del empresario, al compás del avance de la diferenciación, asentada sobre tres ejes fundamentales: un conjunto de negocios amparados y condicionados por el Estado que, en el caso de Vidiella, terminaron concentrándose en la adquisición de deuda pública y en la creación de Agencias de Lotería de Caridad; la compra de bienes inmuebles urbanos; una creciente y constante atención hacia el sector agropecuario, que llevó a la constitución de diferentes establecimientos.

Luego de un viaje a Europa, donde visitó España, Francia y Alemania,28 Francisco Vidiella adquirió, entre 1874 y 1875, una quinta de 25 ha en Villa Colón (Montevideo). Aquí plantó un viñedo, en una de las primeras experimentaciones con este cultivo realizadas en el país, y, luego, construyó una bodega. Su exitosa aclimatación de la cepa Foille Noir, que en el país pasó a llamarse "uva Vidiella", otorgó los primeros retornos económicos al emprendimiento y la granja de Villa Colón se transformó en la cabecera de las otras actividades de la firma.

En 1884, año de su muerte, Francisco conformó el Cortijo Vidiella, de aproximadamente 368 ha en Toledo (Canelones), que, además de viña y bodega, funcionó como cabaña para la venta de animales refinados (vacunos de las razas Durham, Jersey y Shorthorn y ovinos Rambouillet) y también para horticultura, olivicultura e industria lechera. El Cortijo Vidiella estuvo dirigido primero por su hijo Federico y, luego, por su sobrino, Manuel Fortet.

De esta breve descripción se desprende que Vidiella hizo inversiones características de la elite "tradicional" (comercio, propiedades urbanas, especulaciones financieras), otras absolutamente innovadoras (vitivinicultura) y algunas que sería difícil de catalogar (como la creación de Agencias de Loterías). Juzgar sus emprendimientos sobre la base de conceptos tan ambiguos como los que fundamentan la dicotomía "tradicional-moderno" resulta imposible, siempre que no se considere a Vidiella como "tradicional" cuando amplía sus actividades comerciales y "moderno" cuando contribuye a innovar las modalidades de explotación agropecuaria.

Vidiella es todavía recordado como uno de los "padres" de la vitivinicultura uruguaya. A pesar de que el desarrollo industrial de la producción fue muy tardío,

\footnotetext{
${ }^{28}$ La intencionalidad de este viaje, realizado en 1873, es dudosa. Según Luis de la Torre, Vidiella viajó a Europa por razones de placer y durante su estadía quedó "impresionado [...] por los resultados estupendos que se obtenían por allá en los países donde es posible el cultivo de la vid", Luis De la Torre. "Viticultura Nacional". Revista de la Asociación Rural del Uruguay, n 23, año XVI. Montevideo, 15-12-1887; pág. 651. Francisco y otros testimonios de la época aluden a la intencionalidad de este viaje, sustancialmente dedicado al aprendizaje de técnicas y conocimientos vitivinícolas. Posteriormente, el historiador Isidoro De María sostuvo que Francisco Vidiella era "el hijo y nieto de cosecheros del alto Priorato", subrayando con fuerza que detrás de su jornada estaba la intención de recuperar un cultivo que se insertaba en centenarias tradiciones familiares, "Inauguración de la estatua de Vidiella en Villa Colón, el 22 de Marzo de 1891, por don Isidoro De María". Revista de la Asociación Rural del Uruguay, n 6, año XX. Montevideo, 31-3-1891; págs.124125. Sin embargo, pese a que dejó numerosos escritos relacionados a su trayectoria como viticultor, Francisco Vidiella jamás hizo mención a sus ascendentes y, al contrario, insistió en el carácter absolutamente empírico y experimental de su emprendimiento.
} 


\section{Plural ha sido la celeste historia}

visto que todavía en 1887 la bodega de Vidiella superaba apenas el nivel artesanal, ${ }^{29}$ una serie de aciertos en lo que se podría definir como primitiva mercadotecnia, contribuyeron a afianzar su emprendimiento. En 1880 Vidiella ofreció su primera botella de vino al entonces presidente Antonino Vidal y a la directiva de la ARU, anunciando públicamente que tenía 60 bordalesas (unos 12.000 litros) de vino en su bodega, 80.000 cepas plantadas, más de 20.000 plantas en almácigo y que de las 57 variedades con las cuales había ensayado, solamente siete respondían a las condiciones climáticas del sur del país ${ }^{30}$.En 1883 organizó la primera fiesta de la vendimia realizada en el Uruguay. ${ }^{31}$

Además, puso su granja a disposición para visitas y consultas sobre el cultivo de la vid, tanto que tuvo la intención de editar un manual "sobre viticultura arreglado a las condiciones climáticas de este país", del cual en 1880 ya había escrito 78 páginas, y que estaba destinado a instruir aquellos inversionistas que hubiesen querido incursionar en el sector. ${ }^{32}$

La actividad de difusión de los conocimientos vitivinícolas adquiridos empíricamente contribuyó a afianzar una red de intercambio de experiencias entre productores con diferentes niveles de inversión en el sector que, debido al empeño de la ARU -gremial de que Vidiella fue miembro activo- en fomentar e impulsar este tipo de experiencias, tuvo conexiones con análogas relaciones que se estaban verificando en otras zonas del país. ${ }^{33}$

Aunque sobre estas estructuras las noticias a disposición son parciales, es importante señalar, en primer lugar, su rasgo sustancialmente técnico. Las redes servían para difundir los conocimientos vitivinícolas y, en grado menor, saberes técnicos relacionados con otros cultivos y con la ganadería. En este sentido, no fueron pensadas ni sirvieron para conformar sistemas clientelares definidos.

En segundo lugar, que las jerarquías se fundamentaban sustancialmente sobre el nivel de capacitación adquirido por la persona que componía la misma red y no por su posición social. Desde este punto de vista, Francisco Vidiella tuvo un rol central en estas relaciones no por haber alcanzado la cumbre social, sino por el

\footnotetext{
${ }^{29}$ Olivier-Claude-Augustin Poullain Saint-Foix. Étude agricole sur l'Uruguay. Montevideo, Imprenta Rural, 1887, págs. 38-39.

${ }^{30}$ Eduardo Acevedo. Anales históricos del Uruguay, Montevideo, Barreiro y Ramos, 1934; Tomo IV, pág.213; Daniele Bonfanti. Una mina más rica..., Op. Cit.; págs. 93-106.

${ }^{31}$ Alcides Beretta Curi. "Inmigración europea y pioneros en la instalación del viñedo uruguayo". Alcides Beretta Curi (coord.) Del nacimiento de la vitivinicultura a las organizaciones gremiales: la constitución del Centro de Bodegueros del Uruguay. Montevideo, Trilce, 2008; págs.28-29.

32 Francisco Vidiella. "Carta al Sr. Presidente de la Asociación Rural". Revista de la Asociación Rural del Uruguay, $\mathrm{n}^{\circ}$ 10, año XI, Montevideo, 31-5-1880, págs.250-251. En los primeros tres meses de 1887 "más de quinientas personas" habían visitado la Granja Vidiella, F.R.V. (Francisco Vidiella), "Sociedad Vitícola Uruguaya". Revista de la Asociación Rural del Uruguay, n. 6, año XVI. Montevideo, 31-3-1887; pág.142.

${ }^{33}$ Alcides Beretta Curi. "Inmigración europea, elites y redes: la localidad vitivinícola de Mercedes (1870-1916)". Alcides Beretta Curi (ed.) La vitivinicultura uruguaya en la región (1870-2000). Una introducción a estudios y problemas, Montevideo, FHCE, 2010; págs. 53-85 y "Los caminos de innovación en el agro: inmigración, redes de agricultores, elites y viticultura en el Uruguay de la modernización (1870-1900)", Tempos Históricos, Vol.16, Marechal Cândido Rondon. Paraná, 2012; págs. 41-69.
} 


\section{Daniele Bonfanti}

prestigio obtenido con el descubrimiento de una cepa que se adaptaba muy bien a las características climáticas y geológicas del país y a las exigencias de los productores, debido al elevado nivel de productividad de la uva Vidiella. Y también por demostrar una cierta generosidad, parcialmente interesada, en ofrecer las plantas de su vivero a los otros agricultores. ${ }^{34}$ Por ejemplo, Wenceslao Lares, empresario agrícola e industrial de Mercedes que realizó su ascenso social contemporáneamente al de Vidiella, tuvo con él una fluida relación, por contactos personales directos y a través de la ARU. Sin embargo, en ningún momento Lares reconoció algún tipo de subordinación. Ni él ni los otros componentes de estas redes de difusión del conocimiento aceptaron de manera pasiva todos los consejos y las enseñanzas de los principales productores. El hecho de que Vidiella privilegiara algunos vínculos, por ejemplo con Pablo Varzi, empresario industrial, hijo de italianos y también pionero vitivinícola ${ }^{35}$, se debió más a razones de cercanías en la trayectoria como vitivinicultores que a índoles ligadas a un discutible linaje. Sin dudas, el constante ofrecimiento de consejos técnicos y el poner a disposición su experiencia, sus plantas y su establecimiento contribuyeron a fortalecer el prestigio de Vidiella. Pero éste se fundó justamente sobre su disponibilidad y no sobre su sola pertenencia a la elite.

Por último, estas redes difundieron informaciones técnicas a través de sus integrantes. Es decir, el conocimiento se trasmitió siguiendo los nudos de estas estructuras que no necesariamente incluían espacios territoriales próximos o cercanos. Por ejemplo, Vidiella, como se ha visto, estaba en estricta conexión con Pablo Varzi, que tenía un viñedo a pocos kilómetros del suyo, por razones de amistad y de comunión de experimentos, pero también, como se ha visto, con Wenceslao Lares, debido a la importancia de este empresario en los ensayos vitícolas. Estas relaciones sociales permitieron optimizar el crecimiento de algunos sectores, particularmente la vitivinicultura pero también otros ámbitos productivos, a través de la difusión de innovaciones, de especies de plantas adaptadas a la realidad geo-climática del país, de sistemas preventivos contra plagas y enfermedades así como impulsaron el nacimiento de organizaciones empresariales más complejas, como la Sociedad Vitícola Uruguaya de La Cruz (Florida) o la Sociedad Vitícola Salteña, que intentaron superar (exitosamente en el primer caso) los costes de la incorporación tecnológica industrial de las bodegas.

El rasgo familiar de la estructura empresarial implicó una organización jerárquica que, sin embargo, garantizó la temprana inclusión de un sucesor. A la muerte de Francisco, acontecida en 1884, una importante porción de los negocios familiares ya estaba en manos de Federico, suficientemente adiestrado en los

\footnotetext{
34 El reconocimiento a Francisco Vidiella fue tal que no solo recibió premios otorgados por el gobierno y homenajes por parte de la ARU, sino que el 22 de marzo de 1891 se levantó una estatua en su honor en la plaza principal de Colón, la segunda dedicada a una personalidad pública en el país, luego de la estatua a Joaquín Suárez, ilustre notable y dirigente político del período de la independencia.

35 Alcides Beretta Curi. Pablo Varzi. Un temprano espíritu de empresa. Montevideo, Fin de Siglo, 1993.
} 


\section{Plural ha sido la celeste historia}

negocios para que la empresa pudiera sobrevivir y superar la crisis que se habría podido originar con el fallecimiento de su fundador. Federico Vidiella prosiguió y expandió los emprendimientos siguiendo la senda trazada por su padre: sumo cuidado para evitar la dispersión de capitales, pautada reducción de algunas de las anteriores actividades que habían caracterizado a la firma (particularmente el comercio), moderada actividad bursátil, adquisición de bienes raíces urbanos y cuantiosas inversiones agropecuarias, entre las que la vitivinicultura tuvo un lugar preeminente. En 1892 se adquirieron 4.250 ha en las cercanías de la Estación Algorta (Río Negro), que se destinaron al pastoreo de ganado vacuno y lanar, a horticultura, fruticultura y también a vitivinicultura, bajo la dirección del tío José A. Fortet. $^{36}$

La reconstrucción del ascenso social de Francisco Vidiella aparenta ser una mera repetición de otros exitosos empresarios de finales del siglo XIX. La única particularidad es la mala relación con su hermano Juan, algo que parece confirmar algunas dudas expresadas hace dos décadas por Ramella sobre el carácter no necesariamente armónico de las redes étnico-familiares. ${ }^{37}$

En lo que atañe al papel de la red étnica en el ascenso social, su trayectoria puede superponerse a la casi totalidad de los otros miembros de esta elite modernizadora y extenderse a otras realidades latinoamericanas. ${ }^{38}$

Las redes étnicas fueron determinantes para la inserción de estos personajes en el país de acogida y para su ascenso social. Sin embargo, fueron rápidamente abandonadas una vez que estos personajes se consolidaron en la cumbre social.

\section{De las redes primarias al fracaso de las redes de poder}

Un dato provisorio. Sobre un total de 27 familias de extranjeros que conformaron este sector modernizante de la elite uruguaya (jefe llegado en

\footnotetext{
36 Pereda Setembrino E. Río Negro y sus progresos. Montevideo, Imprenta El Siglo Ilustrado, 1898 Vol. I; págs. 275-277.

37 Franco Ramella. "Por un uso fuerte del concepto de red en los estudios migratorios", en María Bjerg y Hernán Otero (comps.). Inmigración y redes sociales en la Argentina moderna. Tandil, CEMLA - IEHS, 1995; págs. 9-21. Asimismo, evidencia las tensiones que pudieron condicionar el proceso de inserción de los inmigrantes en una nueva realidad, en consideración del hecho de que Juan, apartado de la familia, no realizó ningún ascenso social en el país de acogida.

${ }^{38}$ Entre numerosísimos ejemplos, véase a Warren Dean. The industrialization of Sao Paulo, 18801945, Austin, University of Texas Press, 1969 y Darrell E. Levi. The Prados of Sao Paulo. An Elite Family and Social Change, 1840-1930, Athens, University of Georgia Press, 1987, para el caso de Saõ Pablo; Arnold Bauer. Chilean Rural Society from the Spanish conquest to 1930, Cambridge University Press, 2008 (1975), para el caso chileno; Mario Cerutti. "Formación y consolidación de una burguesía regional en el norte de México: Monterrey, de la Reforma a la industria pesada (18501910)". Mario Cerutti y Menno Vellinga (comp.). Burguesías e industria en América Latina y Europa Meridional. Madrid, Alianza, 1989; págs.105-146, para la realidad de Monterrey; Marcos Palacios. Coffee in Colombia, 1850-1970. An economic, social and political history, Cambridge University Press, 2002, sobre el caso del empresariado cafetero colombiano; Beatriz Bragoni. Los hijos de la revolución. Familia, negocios y poder en Mendoza en el siglo XIX. Buenos Aires, Taurus 1999; Roy Hora. Los terratenientes..., Op. Cit. y Andrea Reguera. Patrón de Estancias. Ramón Santamarina: una biografía de fortuna y poder en La Pampa. Buenos Aires, Eudeba, 2006, para el caso argentino.
} 


\section{Daniele Bonfanti}

juventud al país, ascenso entre los años cincuenta y sesenta del siglo XIX, participación directa en el proceso de consolidación de la ARU, llegada a la cumbre social entre 1870 y 1880), en 25 de los casos analizados se puede observar el rasgo endogámico de los casamientos. El matrimonio con descendientes de las familias "patricias" se verifica solamente en el caso de Domingo Ordoñana, impulsor y luego secretario perpetuo de la ARU. ${ }^{39}$ Mientras, el solo Bernardino Pons Tutzó, originario de Mahón (Menorca), constructor, armador naviero y comerciante que llegó a Montevideo luego de un pasaje por Buenos Aires, se casó fuera de su grupo étnico con la italiana María Sipolina. ${ }^{40}$

En el caso de la primera generación de hijos de extranjeros (es decir, ya nacidos en Uruguay) que tuvieron una trayectoria empresarial equivalente a la del grupo anterior el comportamiento matrimonial es menos homogéneo. Por ejemplo, Pablo Varzi, hijo de italianos (en el sentido de súbditos del Reino de Saboya) nacido en Montevideo en 1848, contrajo nupcias con la también descendiente de italianos Sabina Servetti, pero su hermana Teresa casó, contra de la voluntad de su padre, con Julio Levallois, descendiente de franceses. ${ }^{41}$ Por otra parte, no hay información sobre el origen regional de Sabina Servetti y, al respecto, conviene recordar (y subrayar) que el recurso a la categoría nacional tiene un discutible carácter explicativo. ${ }^{42}$ Algo que se hace particularmente evidente en el caso de la familia Varzi, visto que el progenitor Giuseppe había rechazado combatir con la Legión Italiana, al mando de Giuseppe Garibaldi, durante el sitio de Montevideo (1843-1852), alistándose en la Legión Francesa, casi seguramente horrorizado por los principios políticos (republicanísimo, socialismo humanitario) que fundamentaban la constitución de la Legión Italiana.

Los enlaces de la segunda generación de estos empresarios (sean estos extranjeros o nacionales) muestran la superación del carácter étnico (y local) de los enlaces matrimoniales. El comportamiento general es mucho menos definido y definible, aunque se puede encontrar una genérica tendencia en la endogamia social, es decir matrimonios entre miembros de este mismo sector social de

\footnotetext{
39 Juan Pan-Montojo. "El vasco-español Domingo Ordoñana: ruralismo, progreso y orden en el Uruguay del siglo XIX". Pérez Ledesma, Manuel (ed.). Trayectorias transatlánticas (Siglo XIX). Personajes y redes entre España y América. Madrid, Ediciones Polifemos, 2013; págs.269-300.

40 Daniele Bonfanti. "La Granja Pons. Desarrollo y decadencia de una empresa vitivinícola uruguaya (1888-1944)”. Anuario IEHS; $\mathrm{n}^{\circ}$. 25. Tandil, 2010; págs.481-496.

${ }^{41}$ Alcides Beretta Curi y Pablo Varzi..., Op. Cit., págs. 45-50. El caso de Teresa Varzi es bastante emblemático de una nueva realidad, de que Teresa fue una precursora, que se puede vislumbrar a partir de finales del siglo XIX y se consolidará en el siglo XX. Es decir, el casamiento por voluntad propia de los hijos, independientemente del consenso de los padres. El caso más sonado en este sentido fue el del escritor Carlos Genaro Reyles Gutiérrez, nieto de un comerciante británico e hijo de uno de los primeros estancieros innovadores, quien, a pesar de la oposición de su tutor que llegó a denunciarlo, se casó con Antonia Hierro, cantante de una compañía española de zarzuela de gira por Montevideo, José Pedro Barrán y Benjamín Nahum. Historia rural del Uruguay moderno (18511885)..., Op. Cit., págs.343-344. La ley de divorcio por causal de 1907 y por sola voluntad de la mujer de 1913 contribuyeron a incrementar la libertad de elección.

42 Fernando J. Devoto. "Un caso di migrazione precoce. Gli italiani in Uruguay nel secolo XIX". Devoto, Fernando. et alter. L'emigrazione italiana e la formazione dell'Uruguay moderno. Turín, Edizioni della Fondazione Agnelli, 1993; pág. 1.
} 


\section{Plural ha sido la celeste historia}

ascendidos. Mientras en el caso del pionero se privilegió el carácter étnico de las redes de inserción, los hijos eligieron el rasgo social de las mismas redes: habían ascendido socialmente en el ámbito nacional y encontraron relaciones de parentesco con familias con una equivalente trayectoria, independientemente de su origen. ${ }^{43}$

Por ejemplo, Federico Vidiella se casó con Malvina Horne Lavalle, hija del comerciante estadounidense Carlos Ridgely Horne y de Mercedes Lavalle, unión que le permitió estrechar relaciones con el importante sector de empresarios anglófonos residentes en el Río de la Plata. Por cierto, se mantuvieron aquellos nudos familiares heredados que se habían consolidado. Como se ha visto, el tío de Federico, José A. Fortet, se hizo cargo de la dirección del establecimiento en Algorta, mientras su primo Manuel Fortet dirigió el Cortijo Vidiella y, luego, la totalidad de los aspectos agropecuarios de la empresa. Sin embargo, esto se debió a lazos de tipo familiares, en que lo étnico había perdido todo tipo de sentido, entre otras cosas porque José ya había nacido en Uruguay y Manuel representaba la segunda generación de uruguayos de su familia. Es decir, cuándo resisten, las redes étnicas se transformaron en redes afectivas. ${ }^{44}$

También en las actividades económicas comenzó a evidenciarse la "traición" del carácter étnico de las redes, con la inserción de personas juzgadas por su capacitación y no por su origen, como fue en caso del francés Soulez, corresponsal de la firma en Concordia (Argentina) en los años ochenta, que sustituyó a Gutiérrez y Bustillo. 45

Probablemente sería excesivo considerar esta nueva pauta matrimonial como una elección estratégica generalizada, sin embargo tiene una cierta correspondencia con la necesidad de generar unas nuevas redes de articulación más adecuadas a la realidad social del país y, al compás del avance de la regulación institucional, que pudieran generar niveles de negociación con el Estado.

La primera generación huyó de la política, considerada como el espacio de los enfrentamientos militares que hacían menguar las inversiones y las innovaciones. Mientras la segunda se introdujo y fue cooptada como cuadro dirigente y se caracterizó por una destacada trayectoria institucional, correspondiente a su nueva gravitación en la sociedad uruguaya. Esto a pesar del hecho de que los hijos heredaron de los padres el terror al fraccionalismo que derivaba de la política $\mathrm{y}$, por ende, tendieron a apoyar, con mayor o menor entusiasmo, las facciones que se alternaron en el gobierno.

\footnotetext{
${ }^{43}$ Un caso aparte fue el de las familias británicas que se instalaron en la zona de Paysandú y Río Negro entre 1840 y 1850 y que mantuvieron el carácter endogámico de los matrimonios por más tiempo, generalmente una generación más, José Pedro Barrán y Benjamín Nahum. Historia rural del Uruguay moderno (1851-1885)..., Op. Cit, págs. 320-345.

${ }^{44}$ En este marco, se mantuvo la tradicional apertura hacia los extranjeros. Por ejemplo, una de las hijas de Juan Vidiella, Adela Vidiella y Andreu, se casó con el diplomático español Enrique Dupuy de Lòme, mientras Octavia Harriague lo hizo con el dentista y militar estadounidense John Preston Arnes.

45 “Contestación”. Revista de la Asociación Rural del Uruguay, n 3, año XVII. Montevideo, 15-2-1888; pág. 59.
} 
Además de exitoso viñatero y cabañero y de destacado dirigente de la ARU (que presidió desde 1890 hasta 1893), Federico Vidiella fue director titular del Banco Nacional en 1890, Ministro de Hacienda entre 1894 y 1897, miembro del Directorio del Banco Hipotecario durante la primera presidencia de Batlle y Ordoñez (1903-1907), presidente de la Junta Económico Administrativa de Montevideo desde 1907 hasta 1910 y nuevamente Ministro de Hacienda entre 1916 y 1918. La carrera política en el país fue acompañada por la actividad como diplomático en Londres, donde fue Ministro Plenipotenciario en 1909 y, posteriormente, desde 1919 hasta su muerte en 1927. Además de ensanchar las actividades empresariales heredadas, Vidiella fue uno de los inspiradores de la constitución de la Sociedad Vitícola Uruguaya en La Cruz (Florida), sociedad anónima impulsada por la ARU, destinada a resolver los problemas provocados por la escasa tecnificación de las bodegas, promover un negocio que se consideraba con fuertes perspectivas económicas y capacitar la mano de obra rural desempleada, que con el tiempo se transformó en una de las principales bodegas del país. ${ }^{46}$

La entrada en política de Vidiella, compartida por otros empresarios de la segunda generación como Diego Pons, Luís Caviglia o Pablo Varzi (h), supuso un cambio sustancial respecto a la trayectoria de los fundadores de la ARU (y de sus mismos padres). Sin embargo, no parece que esto se debió a la adopción de hipotéticas pautas comportamentales del "patriciado" tradicional. Sino a la toma de conciencia de que los predicamentos de la ARU no se habían concretados y que, para impulsar las innovaciones, era necesario encontrar ámbitos de gestión y dirección desde los cuales se pudieran fomentar las transformaciones deseadas. Al aceptar cargos institucionales, se reconocía que el único agente capaz de impeler este cambio estructural era el Estado.

Por otra parte, al entrar en política la segunda generación se presentó a sí misma como el mejor elenco para impulsar un conjunto de transformaciones diferenciación económica, inversiones productivas y no especulativas, descentralización administrativa- consideradas indispensables para la definitiva consolidación del país, transformaciones que habían caracterizado su trayectoria empresarial.

Para consolidar esta presencia, se hizo un intento de transformar las antiguas redes de difusión del conocimiento generadas por su padre en redes clientelares. Sin embargo, esta conversión se enfrentó con diferentes problemas.

El primero, que se puede generalizar a toda la realidad rioplatense, concernió la dificultad para establecer redes clientelares en el sector agropecuario debido a las características fuertemente estacional del trabajo en el campo y al temprano y rápido proceso de urbanización. ${ }^{47} \mathrm{~A}$ esto hay que sumar el hecho de

\footnotetext{
46 Daniele Bonfanti. Una mina más rica..., Op. Cit., págs. 143-148.

47 Roy Hora y Leandro Losada. "Clases altas y medias en la Argentina, 1880-1930. Notas para una agenda de investigación". Desarrollo Económico, vol. 50, n² 200. Buenos Aires, 2011; págs. 611-630; Leandro Losada. "¿Oligarquía o elites? Estructura y composición de las clases altas de la ciudad de
} 


\section{Plural ha sido la celeste historia}

que, a diferencia de lo acontecido con la elite terrateniente argentina, en Uruguay no se verificó un proceso de desplazamiento definitivo de la residencia en las zonas rurales por parte de este sector, debido al hecho de que parte de las inversiones siguieron siendo urbanas.

Un segundo problema residió en que las redes anteriores no habían sido pensadas ni se habían desarrollado sobre la base de una jerarquía social reconocida, sino a partir de los saberes generados por la experiencia empírica que sus impulsores habían acumulado a lo largo de su vida. En el caso específico, los miembros de la red reconocían a Francisco Vidiella su trayectoria como viticultor, pero no necesariamente estaban dispuestos a extender esta honra a su hijo. Menos aún, luego de que en 1893 se descubrió que el viñedo del Cortijo Vidiella había sido atacado por la filoxera, a pesar de que, como empresario y desde la presidencia de la ARU, el mismo Federico Vidiella se había presentado como un ejemplo a seguir, como viñatero y como impulsor de medidas de prevención de la plaga. ${ }^{48}$ Las redes de difusión de los conocimientos no superaron la crisis filoxérica.

Desde este punto de vista, la década del noventa, inaugurada por una dura crisis económica que parecía confirmar las razones de la prédica de la ARU, particularmente en relación a la necesidad de restar capitales a la especulación financiera para dirigirlos hacia la producción, se concluyó con una serie de acontecimientos que mostraron los límites de esta propuesta.

La aparición de la filoxera indicaba que la capacitación de los empresarios que habían apostado con fuerza a la vitivinicultura era discutible. Las guerras civiles de 1897 y 1904 comprobaron que la pacificación inaugurada por los gobiernos militares de la década de 1870 era muy frágil. Por otra parte, el uso de armas más sofisticadas por parte del ejército para aplastar la rebelión de 1904 indicaba que, para obtener el control social en la campaña no eran necesarios planes integradores. La aparición de los frigoríficos en la primera década de 1900 y su impulso para la ganadería refinada restó argumentaciones a favor de la diversificación de la producción y la sustitución de la ganadería por la agricultura. Es más los frigoríficos y la demanda internacional estaban impulsando un espectacular crecimiento de los precios de los vacunos que siguió constante hasta la finalización de la Primera Guerra Mundial.

\section{Conclusiones provisionales}

A pesar de que sería improcedente llegar a conclusiones firmes, entre otras cosas porque abundan los relatos sobre las trayectorias empresariales exitosas, mientras no existe información sobre los fracasos, creo posible extraer algunas

Buenos Aires entre 1880 y 1930", Hispanic American Historical Review, vol. 87, n 1, 2007; págs. 4375.

48 Daniele Bonfanti. Una mina más rica..., Op. Cit., págs. 167-197 y Domingo Ordoñana. "La Filoxera”. Revista de la Asociación Rural del Uruguay, n 5, año XII. Montevideo; págs. 97-98 y n6, año XII, Montevideo, págs. 124-127. 


\section{Daniele Bonfanti}

ideas que podrían estar en la base de futuras profundizaciones sobre el tema en cuestión.

La evolución de este grupo modernizante confirma la importancia de las redes sociales en la fase de inserción de los inmigrantes en un país -respecto al ámbito laboral y el ascenso social-. Asimismo, indican su significación para facilitar las innovaciones y el cambio tecnológico, aunque, al no ser estas redes ligadas a un territorio específico sino que se extendían en un espacio no predeterminado, implican una revisión de las interpretaciones relacionadas a los mecanismos de difusión de la información.

La ruptura entre los hermanos Vidiella muestra que las redes étnicas y familiares no necesariamente son siempre armónicas y sugiere que las relaciones personales terminan determinando la calidad de la trayectoria de cada componente de una red.

Por otra parte, la evolución fracasada de este sistema pone de manifiesto que un conjunto de relaciones que funcionaron bien en un determinado momento $\mathrm{y}$ aspecto de la realidad social no necesariamente pueden insertarse con la misma eficacia cuando la misma realidad social se modifica.

La justificación última del ascenso político de este grupo empresarial estaba estrictamente ligada al éxito de un proyecto reformista. Al entrar en crisis este último entró en crisis la misma elite. A pesar de que sería discutible considerar que se verificó un empobrecimiento de este sector, es evidente que su gravitación, como punto de referencia intelectual y empresarial, comenzó a menguar a partir de la segunda década del siglo XX. Sus inversiones perdieron el carácter ejemplar y fueron definitivamente delegadas a miembros de la antigua red familiar. Algunos conservaron un rol político, como fue el caso de Federico Vidiella y de Diego Pons, pero cada vez más secundario, hasta terminar su carrera como diplomáticos.

Este sector modernizante de la elite quiso presentarse como el mejor elenco para dirigir el país, intentando trasladar sus éxitos empresariales a la vida pública y sobre la base de la convicción de que, así como "habían hecho" algunos sectores (como la vitivinicultura), bien podían "hacer" un nuevo país. La crisis de estos sectores económicos nuevos (probablemente no "tan bien hechos") llevó a que la apuesta hacia un traslado automático de sus capacidades de la empresa a la gestión política, fracasara antes de que pudiera implementarse.

\section{Fuentes}

Archivo de la Asociación Rural del Uruguay (AARU).

Archivo de la Sociedad Vitícola Uruguaya (ASVU).

Archivo Carlos Varzi (ACV).

Documentos relativos a la fundación de la Asociación Rural del Uruguay, Montevideo, Imprenta del Siglo, 1871.

Revista de la Asociación Rural del Uruguay, Montevideo. 


\section{Plural ha sido la celeste historia}

\section{Bibliografía}

Acevedo, Eduardo. Anales históricos del Uruguay, Montevideo, Barreiro y Ramos, 1934; Tomo IV.

Barrán José Pedro y Nahum Benjamín. Historia rural del Uruguay moderno (18511885). Montevideo, EBO; Tomo I, 1967.

- Historia rural del Uruguay moderno. La crisis económica (1886-1894). Montevideo, EBO; Tomo II, 1971.

- Historia rural del Uruguay moderno. Recuperación y dependencia (1895-1904). Montevideo, EBO; Tomo III, 1973.

- Historia rural del Uruguay moderno. Agricultura, crédito y transporte bajo Batlle (1903-1914). Montevideo, EBO; Tomo VII, 1978.

- Batlle, los estancieros y el Imperio Británico. Un diálogo difícil 1903-1910. Montevideo, EBO; Tomo II, 1981.

- Batlle, los estancieros y el Imperio Británico. El nacimiento del batllismo. Montevideo, EBO; Tomo III, 1986.

Bauer, Arnold. Chilean Rural Society from the Spanish conquest to 1930. Cambridge University Press, 2008 (1975).

Beretta Curi, Alcides. Pablo Varzi. Un temprano espíritu de empresa. Montevideo, Fin de Siglo, 1993.

- "Inmigración europea y pioneros en la instalación del viñedo uruguayo". Beretta Curi, Alcides (coord.) Del nacimiento de la vitivinicultura a las organizaciones gremiales: la constitución del Centro de Bodegueros del Uruguay. Montevideo, Trilce, 2008.

- "Inmigración europea, elites y redes: la localidad vitivinícola de Mercedes (18701916)”. Beretta Curi, Alcides (ed.) La vitivinicultura uruguaya en la región (18702000). Una introducción a estudios y problemas. Montevideo, FHCE, 2010.

- "Los caminos de innovación en el agro: inmigración, redes de agricultores, elites y viticultura en el Uruguay de la modernización (1870-1900)". Tempos Históricos, Vol.16, Marechal Cândido Rondon. Paraná, 2012.

Bonfanti, Daniele. "La Granja Pons. Desarrollo y decadencia de una empresa vitivinícola uruguaya (1888-1944)". Anuario IEHS; ${ }^{\circ}$. 25. Tandil, 2010.

- Una mina más rica que las de oro del Potosí. Elites, técnicos, instituciones y trabajadores en el nacimiento de la vitivinicultura uruguaya (1870-1930), Tesis de doctorado inédita. Madrid, Universidad Complutense - Instituto Universitario de Investigación Ortega y Gasset, 2014.

Bragoni, Beatriz. Los hijos de la revolución. Familia, negocios y poder en Mendoza en el siglo XIX. Buenos Aires, Taurus, 1999.

Cerutti, Mario. "Formación y consolidación de una burguesía regional en el norte de México: Monterrey, de la Reforma a la industria pesada (1850-1910)". Mario Cerutti, Mario y Menno, Vellinga (comp.). Burguesías e industria en América Latina y Europa Meridional. Madrid, Alianza, 1989.

Dean, Warren, The industrialization of Sao Paulo, 1880-1945, Austin, University of Texas Press, 1969.

Devoto, Fernando. "Un caso di migrazione precoce. Gli italiani in Uruguay nel secolo XIX". Devoto, Fernando J. et alter. L'emigrazione italiana e la formazione dell'Uruguay moderno. Turín, Edizioni della Fondazione Agnelli, 1993.

Fernández Saldaña, José María. Diccionario uruguayo de biografías 1810-1940. Montevideo, Amerindia, 1945.

Hora, Roy. Los terratenientes de la pampa Argentina. Una historia social y política, 


\section{Daniele Bonfanti}

1860-1945. Buenos Aires, Siglo XIX, 2005.

Hora Roy y Losada Leandro. "Clases altas y medias en la Argentina, 1880-1930. Notas para una agenda de investigación". Desarrollo Económico, vol. 50, n 200. Buenos Aires, 2011.

Levi, Darrell E. The Prados of Sao Paulo. An Elite Family and Social Change, 18401930, Athens, University of Georgia Press, 1987.

Losada, Leandro, "¿Oligarquía o elites? Estructura y composición de las clases altas de la ciudad de Buenos Aires entre 1880 y 1930", Hispanic American Historical Review, vol. 87, $\mathrm{n}^{\circ} 1,2007$.

Ordoñana, Domingo. Pensamientos rurales sobre necesidades sociales y económicas de la república. Montevideo, Imprenta Rural; Tomo I, 1892.

Palacios, Marcos. Coffee in Colombia, 1850-1970. An economic, social and political history, Cambridge University Press, 2002.

Pan-Montojo, Juan. "El vasco-español Domingo Ordoñana: ruralismo, progreso y orden en el Uruguay del siglo XIX". Pérez Ledesma, Manuel (ed.). Trayectorias transatlánticas (Siglo XIX). Personajes y redes entre España y América. Madrid, Ediciones Polifemos, 2013.

Pereda, Setembrino. Río Negro y sus progresos. Montevideo, Imprenta El Siglo Ilustrado, 1898; Vol. I.

Ramella, Franco. "Por un uso fuerte del concepto de red en los estudios migratorios", en María Bjerg, María y Hernán Otero (comps.) Inmigración y redes sociales en la Argentina moderna. Tandil, CEMLA - IEHS, 1995.

Reguera, Andrea. Patrón de Estancias. Ramón Santamarina: una biografía de fortuna y poder en La Pampa. Buenos Aires, Eudeba, 2006.

Saint-Foix, Olivier-Claude-Augustin Poullain. Saint-Foix, Olivier-Claude-Augustin Poullain. Étude agricole sur l'Uruguay. Montevideo, Imprenta Rural, 1887.

Recibido: $27 / 09 / 2015$

Evaluado: $27 / 10 / 2015$

Versión Final: 05/12/2015 